\title{
ZONEAMENTO ECOLÓGICO-ECONÔMICO DE SILVEIRA MARTINS - RS
}

\author{
ECOLOGICAL-ECONOMIC ZONING OF SILVEIRA MARTINS - RS \\ ZONIFICACIÓN ECOLÓGICA-ECONÓMICA DE SILVEIRA MARTINS - RS
}

\author{
Franciele Francisca Marmentini Rovani - Universidade Federal de Santa Catarina - Florianópolis \\ - Santa Catariana - Brasil
}

Márcio Viera - Universidade Federal de Santa Maria - Santa Maria - Rio Grande do Sul - Brasil

\section{Resumo}

Esta pesquisa teve como objetivo elaborar o Zoneamento Ecológico-Econômico do município de Silveira Martins - RS, integrando informações da vulnerabilidade natural à perda de solo, potencialidade social e áreas de preservação permanente. Para tanto, criou-se um banco de dados espaciais em um ambiente de Sistemas de Informações Geográficas com auxílio do software Spring versão 5.0.6. Utilizou-se informações referentes à geomorfologia, geologia, solos, declividade, rede de drenagem, uso e ocupação da terra, população, economia, educação e saneamento básico. A integração das informações foi realizada por meio da álgebra de mapas. Como resultado destaca-se o mapa do zoneamento com seis zonas. A maior zona é a de conservação $(40,72 \%)$, caracterizada pela alta vulnerabilidade e restrição de potencial social, seguida da zona de consolidação $(37,76 \%)$, compreendendo as áreas produtoras. As zonas de restrição de uso $(10,20 \%)$, constituídas pelas áreas com inclinação entre $25^{\circ}$ a $45^{\circ}$, e de recuperação $(2,50 \%)$, merecem maior atenção quanto às práticas agrícolas. A zona de área de preservação permanente $(7,92 \%)$ também merece destaque quanto às áreas conflitantes. E, por último, a zona urbanizada $(0,90 \%)$, que é constituída pela área urbana. Este cenário atual indica as áreas que merecem maior atenção e intervenção quanto ao planejamento e gestão territorial.

Palavras-chave: Zoneamento ecológico-econômico, vulnerabilidade natural, potencialidade social, geoprocessamento.

\begin{abstract}
This research aimed to elaborate the Ecological-Economic Zoning of Silveira Martins municipality, RS, integrating vulnerability to natural soil loss, social potentiality and permanent preservation areas. Therefore, a spatial database was created in a Geographic Information System (GIS) using Spring 5.0.6 software. Information about geomorphology, geology, soils, slope, drainage network, soil use and occupation, population, economy, education and sanitation was used. Information integrating was performed through map algebra. The map zoning resulted with six zones. Conservation is the largest zone $(40.72 \%)$ characterized by high vulnerability and social potential restriction, followed by consolidation $(37.76 \%)$ characterized by productivity areas. Use restriction zone $(10.20 \%)$, constituted by areas with slope between $25^{\circ}$ and $45^{\circ}$, and recovery zone $(2.5 \%)$, need more attention regarding agricultural practices. Permanent preservation zone $(7.92 \%)$ also needs to be highlighted due to the conflicting areas. Lastly, the urban zone $(0.90 \%)$, which is constituted by urban area. This current scenario indicates areas that deserve more attention and intervention in planning and territorial management.
\end{abstract}

Keywords: Ecological-economic zoning, natural vulnerability, social potentiality; geoprocessing.

\section{Resumen}

Esta investigación tuvo como objetivo elaborar la Zonificación Ecológica-Económica del municipio de Silveira Martins - RS, integrando la información desde la vulnerabilidad natural hasta la pérdida del suelo, potencialidad social y áreas de preservación permanente. Por eso, creamos una base de datos espaciales 
en un ambiente de Sistema de Informaciones Geográficas con el auxilio del software Spring versión 5.0.6. Se utilizaron informaciones sobre la geomorfología, geología, suelos, declividad, red de drenaje, uso y ocupación de la tierra, población, economía, educación y saneamiento básico. La integración de las informaciones se realizó mediante el álgebra de mapas. Como resultado se destaca el mapa de zonificación con seis zonas. El área más grande es la conservación $(40,72 \%)$ que se caracteriza por una alta vulnerabilidad y restricción de potencial social, seguida del área de consolidación $(37,76 \%)$ que comprende las zonas productoras. Las zonas de restricción $(10,20 \%)$, constituidas por las áreas con declividad de $25^{\circ}$ a $45^{\circ}$, y la de recuperación $(2,50 \%)$, merecen mayor atención en relación a las prácticas agrícolas. La zona del área de preservación permanente $(7,92 \%)$ también merece destaque en relación a las áreas en conflicto. Y, por último, la zona urbana $(0,90 \%)$ que está constituida por el área urbana. Este panorama actual indica las áreas que merecen más atención e intervención en la planificación y gestión territorial.

Palabras clave: Zonificación ecológico-económico, vulnerabilidad natural, potencial social, geoprocesamiento.

\section{Introdução}

No sentido de tornar compatível o desenvolvimento econômicosocial com a preservação da qualidade do meio ambiente e do equilíbrio ecológico, destaca-se uma preocupação de âmbito nacional, inerente à Política Nacional do Meio Ambiente (PNMA), estabelecendo os zoneamentos como um de seus instrumentos. Inicialmente planejado para a Amazônia Legal e, posteriormente, ampliado para o território nacional, o Zoneamento Ecológico-Econômico (ZEE) é um instrumento de planejamento e ordenamento territorial que busca a sustentabilidade ecológica, econômica e social, dividindo o território em zonas, de acordo com as necessidades de proteção, conservação, recuperação dos recursos naturais e do desenvolvimento sustentável.

Os zoneamentos aplicados às regiões estratégicas possibilitam uma grande base de dados geográficos, geralmente em um ambiente de Sistema de Informações Geográficas (SIG). Estes instrumentos auxiliam na tomada de decisões no planejamento do ordenamento territorial, em diversos segmentos sociais, e na ação efetiva de gestores públicos. Com base na análise do meio físico-biótico, da dinâmica socioeconômica e da organização jurídico-institucional torna-se possível identificar as potencialidades e fragilidades do meio, as limitações e as oportunidades dos usos potenciais e representar graficamente os cenários.

O ZEE apresenta informações sobre o território, necessárias para planejar a sua ocupação racional e o uso sustentável dos recursos naturais, integradas em uma base geográfica de dados (Campagnani; Santos, 1998). Além disso, é possível identificar áreas do território, segundo potencialidades e vulnerabilidades naturais, fundamentais para o processo de compreensão do cenário atual, integrando políticas 
públicas e colaborando para o processo de tomada de decisões para o ordenamento territorial. Desta forma, entende-se que a potencialidade indica o quanto uma área apresenta possibilidade de desenvolvimento considerando os aspectos sociais. E, a vulnerabilidade natural, refere-se ao quanto aquela área é frágil diante das condições ambientais atuais, indicando recuperação ou conservação do meio.

Nesse sentido, metodologias foram desenvolvidas visando a elaboração deste instrumento de planejamento e gestão, destacando-se a metodologia para o ZEE, desenvolvida e aplicada inicialmente à Amazônia Legal. Esta proposta visava integrar aspectos naturais, por meio da avaliação da vulnerabilidade da paisagem natural, e aspectos sociais e econômicos, considerando a potencialidade social. De acordo com Crepani et al. (1996), a carta de vulnerabilidade natural, baseada no princípio da ecodinâmica de Tricart (1977), considera os processos de morfogênese e pedogênese a partir da análise integrada (solo, rocha, vegetação e clima). A carta de potencialidade social, segundo Becker e Egler (1996), considera a relação entre os fatores dinâmicos e os fatores restritivos de acordo com os dados econômicos, sociais e políticos. A integração de ambas as cartas resulta em uma carta-síntese conforme a potencialidade ou vulnerabilidade da paisagem.

Em outra aplicação da metodologia de ZEE desenvolvida por Simões et al. (1998, p. 4) ao Médio Vale Paraíba do Rio de Janeiro, os autores salientam que "o conhecimento da vulnerabilidade natural é fundamental para prever o comportamento futuro dos sistemas naturais diante do processo de ocupação e adensamento da atividade social". Além disso, enfatizam que "a análise da potencialidade social deve buscar identificar a capacidade das unidades territoriais em constituírem-se em espaços de mudança, isto é, gerar, difundir e absorver inovações que promovam o desenvolvimento endógeno [...]" (Simões et al., 1998, p. 4). Assim, a análise da vulnerabilidade natural à perda do solo associada ao estudo do potencial social é fundamental na elaboração deste instrumento de planejamento territorial.

Ressalta-se a importância destes estudos, que se fundamentam na integração dos aspectos naturais, sociais e institucionais de um determinado espaço geográfico em uma mesma base cartográfica. Corroborando com esta ideia, Pereira et al. (2011) destaca que o ZEE constitui-se em um instrumento de gestão social em que o enfoque 
territorial tornou-se referência para os estudos sobre desenvolvimento e gestão social. Além disso, nos trabalhos desenvolvidos por Mesquita, Assis e Souza (2010), Lima et al. (2011) e Rovani, Sartori e Cassol (2014), os autores destacam resultados conclusivos quanto a análise da vulnerabilidade natural à perda de solo e da potencialidade social, podendo assim definir áreas estratégicas de planejamento e gestão territoriais orientadas pelos principais elementos que influenciam e constituem estes cenários.

Nesta perspectiva, destaca-se o município de Silveira Martins, localizado na Região da Quarta Colônia de Imigração Italiana do Rio Grande do Sul, como uma área importante para o desenvolvimento social e ambiental. Pensando a região em sua diversidade de atividades econômicas, do potencial turístico e da riqueza natural, visou-se elaborar o Zoneamento Ecológico-Econômico do município de Silveira Martins, integrando a vulnerabilidade natural, a potencialidade social e as áreas de preservação permanente.

O município de Silveira Martins está localizado na Quarta Colônia de Imigração Italiana (Figura 1), na região central do estado do Rio Grande do Sul, na transição geomorfológica entre a Depressão Periférica e o Planalto da Serra Geral, entre os Biomas Mata Atlântica e Pampa. O município possui área total de $118,42 \mathrm{~km}^{2}$ e 2.449 habitantes, sendo que 1.091 residem na zona urbana e 1.358 na zona rural (IBGE, 2014). Predominam as atividades agropecuárias, com a presença das lavouras temporárias de milho, soja e feijão, totalizando 91\% das áreas cultivadas (IBGE, 2006).

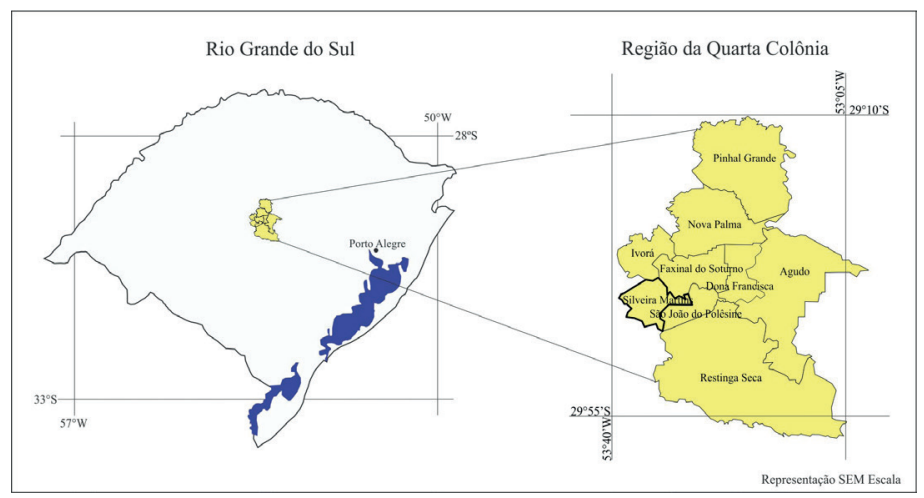

Figura 01 - Localização do município de Silveira Martins - RS 


\section{Materiais e métodos}

Para a realização desta pesquisa foi necessário coletar dados para a elaboração da base cartográfica do município de Silveira Martins. Esta foi elaborada com os dados georreferenciados da Base Cartográfica Vetorial Contínua do Rio Grande do Sul, na escala 1/50.000, organizados por Hasenack e Weber (2010). Utilizou-se, também, a malha digital dos setores censitários em formato shapefile, no Datum Sirgas 2000, adquirida junto ao Instituto Brasileiro de Geografia e Estatística (IBGE).

Os dados necessários para a análise da vulnerabilidade natural à perda do solo foram: uma imagem orbital sem correção geométrica do satélite Landsat 8 (bandas 4, 5, 6), sensor OLI/TIRS, órbita 223/80, data da passagem 12 de junho de 2014; mapas temáticos preexistentes de geologia (IBGE, 2003a) e geomorfologia (IBGE, 2003b) obtidos junto ao IBGE, na escala 1:250.000; e o mapa temático de solos, obtido do livro "Solos do Rio Grande do Sul” (Streck et al., 2008).

$\mathrm{Na}$ análise da potencialidade social utilizaram-se os dados do censo demográfico de 2010 (IBGE, 2010) e do censo agropecuário de 2006 (IBGE, 2006), referentes ao município de Silveira Martins, coletados juntos ao IBGE. Os dados econômicos do município foram coletados na Fundação de Economia e Estatística do Rio Grande do Sul (FEE).

Para o processamento das informações foram utilizados os seguintes softwares: Spring versão 5.0.6, para a elaboração do banco de dados e edição; CorelDRAW X6, para a edição final dos mapas temáticos; Microsoft Office Excel 2007, para a compilação de dados em gráficos e tabelas; um GPS (Global Positioning System) Garmim, para coleta dos dados a campo; e uma câmera fotográfica, para registro dos dados verificados em campo.

De posse dos dados, elaborou-se o banco de dados geográficos com auxílio do software Spring versão 5.0.6, no qual foram armazenadas todas as informações referentes aos aspectos sociais, econômicos e naturais do município. Por meio da álgebra de mapas integraram-se os dados referentes aos aspectos sociais, físicos e legais (áreas de preservação permanente), resultando no mapa do zoneamento ecológico-econômico.

Para tanto, a álgebra de mapas foi executada através de programas de Linguagem Espacial para Geoprocessamento Algébrico (LEGAL) no Spring. Dessa forma, cada tema foi analisado individualmente, de acordo com a relação morfogênese/pedogênese (temas físicos), e foi atribuído um grau 
de estabilidade/vulnerabilidade a eles; já para os temas socioeconômicos, observou-se a relação dinamismo/restrição e atribuiu-se um grau de baixo/ alto potencial. Na álgebra de mapas, utilizaram-se operações pontuais e zonais.

A análise do potencial social e sua representação cartográfica tiveram como base a metodologia indicada por Becker e Egler (1996). Seguindo esta proposta, a potencialidade de cada setor censitário foi estabelecida de acordo com a relação entre os fatores dinâmicos e os fatores restritivos, em termos econômicos, sociais e políticos, a partir de quatro grupos de parâmetros considerados como componentes básicos para o desenvolvimento sustentável: potencial produtivo, institucional, natural e humano. O setor censitário um, com área de 106,31 ha (0,9\% do total do território municipal), corresponde à área urbanizada do município e, portanto, não fez parte da análise do potencial social, por possuir uma dinâmica diferente dos demais setores situados no meio rural. Os setores dois, três e quatro correspondem a $28,97 \%, 34,12 \%$ e $36,01 \%$, respectivamente, do município de Silveira Martins, e estão localizados na área rural.

O potencial produtivo foi obtido com base nas informações de: densidade rodoviária $(\mathrm{km})$, rendimento por domicílio (R\$), rendimento do chefe de família $(\mathrm{R} \$)$, rentabilidade agropecuária $(\mathrm{R} \$)$ e uso e ocupação da terra (classes em hectare - floresta nativa, culturas, campo, área urbanizada, solo exposto e açudes). Para analisar o uso e ocupação da terra utilizou-se a imagem de satélite e a partir do processamento digital da imagem e com a validação dos dados em campo, obtiveram-se as classes de uso.

O potencial institucional foi constituído pelos dados referentes à autonomia política/administrativa (receitas e despesas, em R\$, do município em 2010) e à participação político/eleitoral (número de votantes na última eleição, 2012). O potencial natural levou em consideração os dados de cobertura florestal (ha) e aptidão agrícola dos solos (por classe de solo).

O potencial humano foi elaborado com base nos dados obtidos junto ao IBGE (2010) referentes ao censo demográfico, de: serviços da saúde (números de leitos), abastecimento de água (rede geral, poço ou nascente, água da chuva em cisternas ou outras fontes), saneamento domiciliar (ligados à rede geral, com fossa séptica, com esgoto em fossa rudimentar, 
com instalação sanitária lançando em vala negra, com lançamento em rio, lago ou mar, com lançamento em escoadouro ou sem esgoto), coleta de lixo (por serviço de limpeza, coletado em caçamba, queimado, jogado em terreno baldio, jogado em rio, lago ou mar ou jogado em outro lugar), alfabetização (pessoas alfabetizadas com cinco ou mais anos de idade) e energia elétrica (estabelecimento domiciliar com ou sem energia elétrica). De acordo com a análise integrada destes quatro grupos, o potencial social de cada setor foi expresso em valores de potencial alto, médio e baixo (Tabela 01).

Tabela 01 - Avaliação do potencial social de acordo com o dinamismo/restrição

\begin{tabular}{c|c|c}
\hline Potencial & Condições para o desenvolvimento humano & Valor \\
\hline Alto & Prevalecem os fatores dinâmicos & 3,0 \\
Médio & Equivalência entre os valores dinâmicos e restritivos & 2,0 \\
Baixo & Prevalecem os fatores restritivos & 1,0 \\
\hline
\end{tabular}

Fonte: Becker e Egler (1996).

A integração dos quatro potenciais, após serem valorados, deu-se por meio de uma média ponderada observando-se o número de indicadores em cada grupo de parâmetros. A representação final do potencial social seguiu uma escala de potencial alto/baixo com cinco classes: baixo (valores entre 1,0 a 1,39); moderadamente baixo (valores entre 1,4 a 1,79); medianamente baixo/alto (valores entre 1,8 a 2,29); moderadamente alto (valores entre 2,3 a 2,69) e alto (valores entre 2,7 a 3,0). Desta forma, para o arredondamento dos valores, considerou-se até duas casas decimais.

Para a análise da vulnerabilidade natural à perda de solo utilizou-se a metodologia elaborada por Crepani et al. (1996), que propõe uma classificação do grau de estabilidade ou vulnerabilidade (resistência ao processo natural à erosão), segundo as relações de morfogênese e pedogênese, a partir da análise integrada das rochas, do solo, do relevo e do clima. Desse modo, quando predomina a morfogênese, prevalecem os processos erosivos modificadores da forma do relevo, e, quando predomina a pedogênese, prevalecem os processos formadores do solo. Para a análise da vulnerabilidade natural à perda de solo utilizaram-se os dados de solos, geologia, geomorfologia e declividade, espacializados de acordo com as Unidades Territoriais Básicas (UTBs) identificadas no município. 
As UTBs são as células elementares de informação e análise para o ZEE (Becker; Egler, 1996). Estas unidades são entidades geográficas que contêm atributos ambientais e vínculos dinâmicos, formando uma complexa rede integrada (Crepani et al., 1996).

Os mapas temáticos preexistentes de solos, geologia e geomorfologia foram digitalizados manualmente no Spring. Para o mapa de geomorfologia, as classes foram editadas e reclassificadas de acordo com as características do relevo verificadas com auxílio da imagem de satélite e in loco. O mapa temático de declividade foi obtido a partir do modelo numérico do terreno, com base nas cartas topográficas. Definiram-se seis classes de declividade: classe $0^{\circ}$ a $3^{\circ} ; 3,1^{\circ}$ a $7,0^{\circ} ; 7,1^{\circ}$ a $17,0^{\circ} ; 17,1^{\circ}$ a $25,0^{\circ} ; 25,1^{\circ}$ a $45^{\circ}$ e classe superior a $45^{\circ}$. A identificação e delimitação das UTBs foram elaboradas a partir da interpretação visual da imagem de satélite.

A vulnerabilidade ou estabilidade foi expressa pela atribuição de valores de acordo com a relação pedogênese/morfogênese em uma escala de 1 a 3 (Tabela 02).

Tabela 02 - Avaliação da estabilidade/vulnerabilidade de acordo com a relação pedogênese/morfogênese

\begin{tabular}{ccc}
\hline Unidade & Relação pedogênese/morfogênese & Valor \\
\hline Estável & Prevalece a pedogênese & 1,0 \\
Intermediária & Equilíbrio entre a pedogênese e a morfogênese & 2,0 \\
Instável & Prevalece a morfogênese & 3,0 \\
\hline
\end{tabular}

Fonte: Crepani et al. (1996), modificada de Tricart (1977).

As classes de cada mapa temático foram substituídas pelos valores de vulnerabilidade preestabelecidos no SIG. Em seguida, por meio de operações de álgebra de mapas, utilizando a linguagem de programação, os atributos de cada mapa foram integrados por meio de uma média aritmética. Desta operação, que integrou os quatro temas físicos, resultou um novo arquivo que representou a vulnerabilidade natural à perda de solo.

As unidades que apresentaram valores entre 1,0 a 1,39 foram definidas como estáveis, as que apresentaram valores de 1,4 a 1,79 foram classificadas de moderadamente estável. Os valores no intervalo de 1,8 a 2,29 definiram a classe de medianamente estável/vulnerável, os valores entre 2,3 a 2,69 determinaram a classe de moderadamente vulnerável e, 
por fim, as unidades com valores entre 2,7 a 3,0 foram classificadas de vulneráveis. Para o arredondamento dos valores, considerou-se, até duas casas decimais.

Na identificação das áreas de preservação permanente utilizou-se o auxílio das cartas topográficas e da imagem de satélite. Com base na rede de drenagem digitalizada, definiu-se como áreas de APPs as margens dos cursos d'água com até 10 metros de largura e o entorno das nascentes. Utilizou-se um raio de 30 metros para definir as APPs nas margens dos cursos d'água e 50 metros para o entorno das nascentes. As declividades superiores a $45^{\circ}$, consideradas APPs, foram identificadas com base no mapa de declividade obtido por meio do Modelo Número do Terreno (MNT).

A elaboração do Zoneamento Ecológico-Econômico, síntese das informações, consistiu na integração dos dados de vulnerabilidade natural à perda de solo das áreas de preservação permanente, incluindo a área de abrangência do núcleo da Reserva da Biosfera em Silveira Martins e dos dados do potencial social, por meio da álgebra de mapas. Este produto servirá como subsídio para a gestão ambiental na região, integrando os aspectos naturais e humanos presentes na paisagem.

A síntese do agrupamento resultou em unidades (zonas) relativamente homogêneas, mas não estáticas, isto é, unidades que poderão expandir ou não sua área de acordo com iniciativas de implementação e ações ambientais. A definição dessas unidades resultou em áreas de consolidação, recuperação, conservação, restrição de uso, preservação permanente e uso urbano, de acordo com o grau de vulnerabilidade e/ou estabilidade natural e do grau de dinamismo e/ou restrição social.

\section{Resultados e Discussões}

\section{Potencialidade Social}

O potencial social foi obtido a partir da análise das informações provenientes dos potenciais natural, humano, produtivo e institucional com base nos setores censitários. Estes são as menores unidades territoriais, formados por áreas contínuas, integralmente contidas em área urbana ou rural, com dimensão adequada para a coleta de dados durante a realização do censo pelo IBGE. O município de Silveira Martins é dividido em quatro setores censitários, como pode ser observado na Figura 02. 


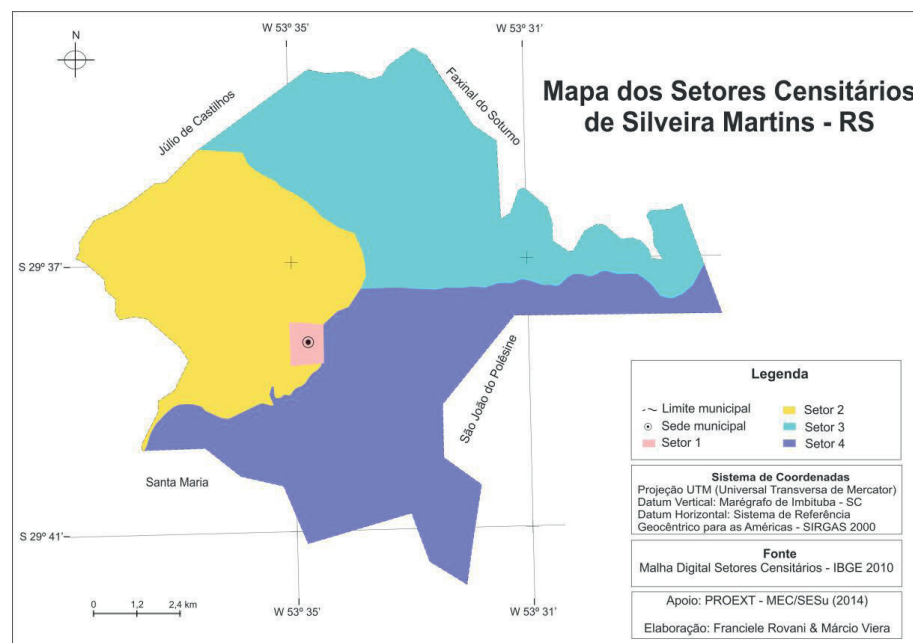

Figura 02 - Mapa da distribuição dos setores censitários do IBGE em Silveira Martins - RS

Fonte: Elaborado pelos autores.

O Município possui homogeneidade da potencialidade, demonstrando um equilíbrio entre o dinamismo e a restrição. Esta representação do potencial social visou principalmente identificar os fatores impulsionadores do desenvolvimento endógeno do município, bem como aqueles que apresentaram restrições e merecem ser destacados, pois possivelmente apresentarão novos cenários, se decisões concretas forem tomadas.

Todos os setores censitários localizados na área rural do município apresentaram potencial social mediano (valor entre 1,80 e 2,39), com valores variando de 2,13 a 2,20. O setor censitário dois destaca-se com o maior valor do potencial humano $(2,28)$; para o setor três, destaca-se o potencial institucional $(2,25)$; e para o setor quatro, o potencial humano $(2,36)$. Esse cenário indica que os três setores apresentam potencialidades de desenvolvimento, especialmente com relação ao potencial produtivo, importante parâmetro no meio rural e do potencial humano. A diversidade produtiva, bem como a integração do sistema viário, o acesso à saúde, ao saneamento e ao ensino são indicadores que merecem destaque.

Para os três setores, o potencial natural foi o de menor valor entre todos os potenciais. O setor dois, três e quatro apresentaram, 
respectivamente, os seguintes valores: 1,82, 2,01 e 1,94. Isso demonstra que a aptidão agrícola dos solos é baixa em mais de 62\% do território municipal. Essas áreas são de abrangência do Neossolo Regolítico Eutrófico, que são solos jovens e que apresentam certas restrições para culturas anuais. Segundo Streck et al. (2008), esses solos podem ser cultivados quando a declividade for menor que $15 \%$ e mediante práticas intensivas de conservação, com mínima mobilização do solo.

\section{Vulnerabilidade Natural à Perda do solo}

A identificação da vulnerabilidade natural à perda do solo resultou da integração das informações referentes aos valores de estabilidade/ vulnerabilidade dos solos, da geomorfologia, da geologia e da declividade do terreno com base nas unidades territoriais básicas. Identificou-se a presença das cinco classes de estabilidade/vulnerabilidade, com predomínio da classe medianamente estável/vulnerável (Figura 03).

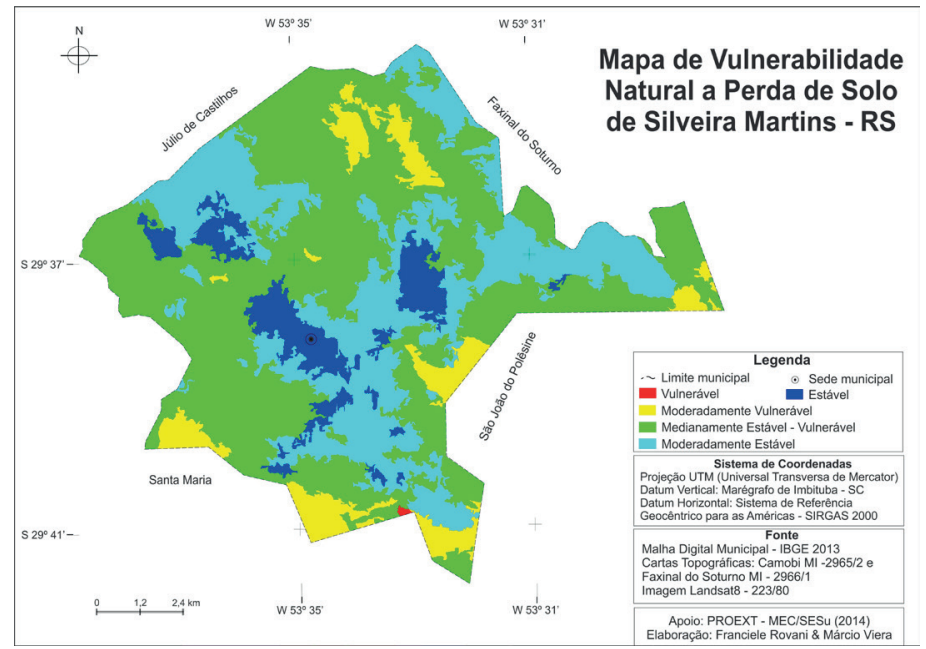

Figura 03 - Mapa da Vulnerabilidade Natural à perda de solo em Silveira Martins - RS Fonte: Elaborado pelos autores.

As áreas mais estáveis (classe estável e moderadamente estável) à perda de solo representam as áreas relativamente homogêneas com 
relação às características de solo, geologia, geomorfologia e declividade, totalizando 38,08\% da área municipal. Estão situadas principalmente nas áreas com menor inclinação do relevo e na formação geológica Serra Geral, constituída por rochas com maior grau de coesão, como o basalto, quando comparadas aos arenitos, aos xistos, de menor grau de coesão.

As áreas identificadas como medianamente estáveis/vulneráveis, em maior proporção (53,67\%), estão na transição entre as unidades mais estáveis e as mais vulneráveis, sendo encontradas na maior parte territorial. Essas áreas apresentam um equilíbrio entre os processos de pedogênese e morfogênese (Mesquita et al., 2010; Rovani et al., 2015). As áreas classificadas como moderadamente vulneráveis e vulneráveis $(8,25 \%$ do total), correspondem a porções do relevo com inclinações elevadas $\left(>25^{\circ}\right)$ e com formação geológica e geomorfológica menos estáveis.

\section{Áreas de preservação permanente (APPS)}

O município de Silveira Martins possuiu, conforme as definições da Lei $n^{0}$ 12.651, de 25 de maio de 2012 (BRASIL, 2012), conhecida como Novo Código Florestal, 935,04 ha de áreas de preservação permanente, isto é, 7,9\% de sua área territorial (Figura 04).

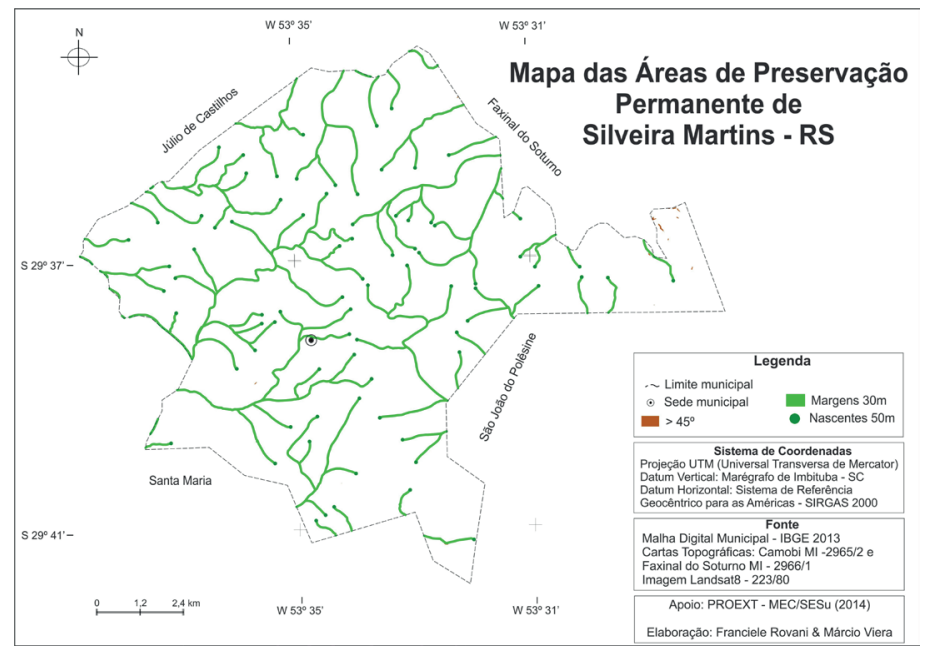

Figura 04 - Mapa das Áreas de Preservação Permanente em Silveira Martins - RS 
Conforme a Lei $\mathrm{n}^{0} 12.651$, a área de preservação permanente é definida como "área protegida, coberta ou não por vegetação nativa, com a função ambiental de preservar os recursos hídricos, a paisagem, a estabilidade geológica e a biodiversidade, facilitar o fluxo gênico de fauna e flora, proteger o solo e assegurar o bem-estar das populações humanas" (BRASIL, 2012, Art. $3^{\circ}$ ).

Os cursos d'água em Silveira Martins possuem leitos com calha inferior a 10 metros de largura. Dessa forma, a projeção da área de preservação permanente em margens de rios, nascentes e encostas são definidas, com base no Código Florestal, como: I - as faixas marginais de qualquer curso d'água natural perene e intermitente, excluídos os efêmeros, desde a borda da calha do leito regular, em largura mínima de 30 (trinta) metros, para os cursos d'água de menos de 10 (dez) metros de largura; IV - as áreas no entorno das nascentes e dos olhos d'água perenes, qualquer que seja sua situação topográfica, no raio mínimo de 50 (cinquenta) metros; $\mathrm{V}$ - as encostas ou partes destas com declividade superior a $45^{\circ}$, equivalente a $100 \%$ (cem por cento) na linha de maior declive (BRASIL, 2012, Art. $4^{\circ}$ ).

As áreas de preservação permanente em margens de cursos d'água com até 10 metros de largura, totalizam 868,7 ha. As áreas de preservação permanente em torno das nascentes, considerando um raio de 50 metros, são de 63,5 ha. Já em áreas com declividades superiores a $45^{\circ}$, são apenas 2,84 ha. Dessa forma, as áreas de preservação permanente em margens de rios, correspondem a 92,9\% do total, seguido pelas áreas em torno das nascentes $(6,8 \%)$ e declividade superior a $45^{\circ}(0,30 \%)$.

\section{Zoneamento Ecológico-Econômico}

O resultado da integração das informações ambientais e sociais é o mapa do Zoneamento Ecológico-Econômico (Figura 05).

O ZEE apresenta zonas que possibilitam a sensibilização aos problemas ambientais e sociais, destinados não somente à conscientização do estado da dinâmica ambiental, mas também para subsidiar as ações e decisões no planejamento territorial. Esta representação possibilitou definir zonas com maior ou menor potencial produtivo e/ou de conservação. As zonas definidas no ZEE são: 


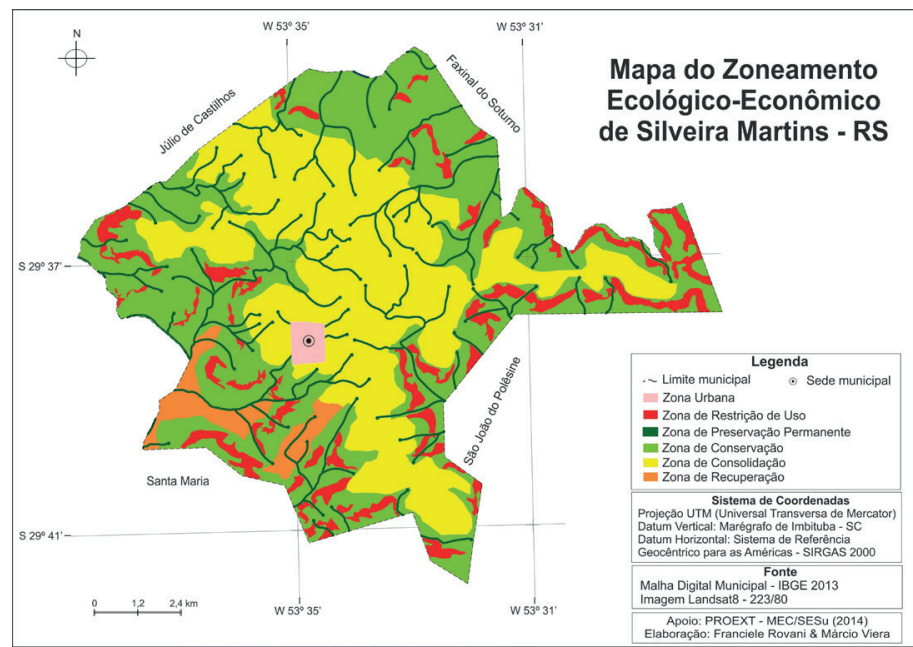

Figura 05 - Mapa temático do Zoneamento Ecológico-Econômico de Silveira Martins - RS

Fonte: Elaborado pelos autores.

- Zona Urbana: A área urbanizada mapeada compreende o perímetro urbano definido pelos setores censitários, representando 0,90\% de sua área total (106,18 ha).

- Zona de Restrição de Uso: São áreas com inclinação entre $25^{\circ}$ e $45^{\circ}$ (10,2\% do município). Conforme o Art. 11 da Lei 12.651, de 25 de maio de 2012, em áreas de inclinação entre $25^{\circ}$ e $45^{\circ}$ serão permitidos o manejo florestal sustentável e o exercício de atividades agrossilvipastoris, bem como a manutenção da infraestrutura física associada ao desenvolvimento das atividades, observadas boas práticas agronômicas, sendo vedada a conversão de novas áreas, excetuadas as hipóteses de utilidade pública e interesse social (BRASIL, 2012, Art. 11).

- Zona de Preservação Permanente (APPs): Áreas definidas como “área protegida, coberta ou não por vegetação nativa, com a função ambiental de preservar os recursos hídricos, a paisagem, a estabilidade geológica e a biodiversidade, facilitar o fluxo gênico de fauna e flora, proteger o solo e assegurar o bem-estar das populações humanas" (BRASIL, 2012, Art. $3^{\circ}$ ). O município de Silveira Martins possuiu 935,04 ha de área de preservação permanente, localizadas em margens de cursos d'água, nascentes e em áreas com declividades superiores a $45^{\circ}$. 
- Zona de Conservação: Correspondem a 40,72\% do território municipal (4.821,88 ha) e estão localizadas na transição entre as unidades geomorfológicas do Planalto e da Depressão Periférica. São zonas com elevado grau de vulnerabilidade natural e que apresentam restrições no potencial social. Estas unidades possibilitam o uso racional e sustentável dos recursos naturais, visando manter uma harmonia entre o homem e o meio. As boas práticas sociais associadas às políticas ambientais no processo de tomada de decisões econômicas possibilitam a valorização e proteção do meio natural. Além do mais, grande parte desta zona de conservação definida no município de Silveira Martins corresponde à parte da zona núcleo da Reserva da Biosfera da Mata Atlântica na região da Quarta Colônia Italiana.

- Zona de Recuperação: As unidades críticas de recuperação representaram $2,5 \%$ da área municipal (296,63 ha) e estão localizadas especialmente na área de influência da Reserva da Biosfera. Suas principais características são o alto potencial social com atividades agroindustriais e turismo ecológico, mas apresentando significativa vulnerabilidade natural. O alto potencial favorece o desenvolvimento social e a dinâmica que, no entanto, são restringidos pela presença da vulnerabilidade natural do ambiente. Deste modo, a adequação destas unidades deve estar baseada na recuperação das condições de solo e ambiente, visando a obtenção de uma estabilidade do meio e na melhoria da qualidade do ambiente e da vida das pessoas. Para que ocorra a recuperação dessas zonas, deve-se optar por modelos produtivos com o mínimo de interferência no solo e na vegetação. Pode-se adotar a utilização de sistemas agroflorestais, que são caracterizados pela combinação da produção agrícola e florestal simultânea ou consecutiva, de forma deliberada, na mesma unidade de terreno, almejando um aumento de produtividade do solo através de um rendimento sustentado, por meio da aplicação de técnicas de manejo compatíveis com as práticas culturais da população local.

- Zona de Consolidação: As unidades produtivas foram classificadas em zonas de consolidação ou de fortalecimento do desenvolvimento humano (baixa vulnerabilidade e maior potencialidade). Estão situadas predominantemente na região geomorfológica do Planalto e estas unidades produtivas representam 37,76\% da área municipal (4.471,94 ha). Pode-se afirmar que suas características indicam o fortalecimento do desenvolvimento humano, sobretudo pela baixa vulnerabilidade natural e 
maior potencialidade social. Isto indica que estas unidades são potenciais para o desenvolvimento produtivo, diante do potencial social apresentado e das áreas de estabilidade natural. A zona de consolidação de Silveira Martins corresponde às áreas com cultivos agrícolas já estabelecidos, e com áreas destinadas à pecuária. Essas áreas são formadas por estruturas geológicas e geomorfológicas mais estáveis e, também, por apresentarem baixa declividade (menor que $25^{\circ}$ ).

\section{Considerações Finais}

O potencial social do município de Silveira Martins apresentou um equilíbrio entre o dinamismo e a restrição, indicando um potencial mediano. A análise da vulnerabilidade natural à perda do solo mostrou predomínio das áreas medianamente estáveis/vulneráveis (53,67\%), apontando uma transição entre as unidades estáveis e vulneráveis. Quanto às áreas de preservação permanente, 7,92\% da área municipal, merecem especial atenção quanto às áreas conflitantes de uso.

No mapa do zoneamento ecológico-econômico destacam-se seis zonas. A maior zona é a de conservação (40,72\%), caracterizada pela alta vulnerabilidade e restrição de potencial social, seguida da zona de consolidação (37,76\%), compreendendo as áreas produtoras. As zonas de restrição de uso $(10,20 \%)$, constituídas pelas áreas com inclinação entre $25^{\circ}$ a $45^{\circ}$, e de recuperação $(2,50 \%)$, merecem maior atenção quanto às práticas agrícolas. A zona de área de preservação permanente (7,92\%) também merece destaque quanto às áreas conflitantes. E, por último, a zona urbanizada (0,90\%), que é constituída pela área urbana.

Este cenário atual apresenta a distribuição e identificação das áreas que deverão ser observadas na implementação do planejamento e gestão do município de Silveira Martins, segundo suas características. De posse desse instrumento, os gestores municipais poderão definir ações que visem à valorização destes espaços naturais, identificados especialmente pela sua vulnerabilidade, e o desenvolvimento econômico municipal pautado em bases sociais, culturais e ecologicamente sustentáveis. Sugere-se, a partir desta análise, o desenvolvimento de novos estudos para o Município em escala cartográfica maior, podendo assim identificar detalhes e/ou aspectos que não puderam ver visualizados nesta pesquisa em função da escala adotada, visando otimizar o planejamento territorial. 


\section{Nota}

Este estudo teve apoio financeiro concedido pelo PROEXT - MEC/SESU durante o ano de 2014.

\section{Referências}

BECKER, B. K.; EGLER, C. A. G. Detalhamento da Metodologia para Execução do Zoneamento Ecológico Econômico pelos Estados da Amazônia Legal. Brasília: SAE/MMA, 1996.

BRASIL. Presidência da República (2012). Lei n 12.651 de 25 de maio de 2012. Institui o Código Florestal Brasileiro. Disponível em: <http://www.planalto.gov. br/ccivil_03/_ato2011-2014/2012/lei/l12651.htm>. Acesso em: 07 jun. 2014.

CAMPAGNANI, S.; SANTOS, U. P. dos. Programa de Zoneamento EcológicoEconômico do estado do Rio de Janeiro. Projeto II: Zoneamento EcológicoEconômico do Médio Vale do Paraíba. Rio de Janeiro, 1998.

CREPANI, E. et al. Curso de Sensoriamento Remoto Aplicado ao Zoneamento Ecológico-Econômico. São José dos Campos: INPE, 1996. 18 p.

HASENACK, H.; WEBER, E. Base cartográfica vetorial contínua do Rio Grande do Sul. Série Geoprocessamento. Porto Alegre, 2010. 1 CD-ROM. Escala 1:50000.

IBGE. Geologia. Santa Maria SH.22-V-C. Rio de Janeiro: IBGE, 2003a. 1 mapa. Escala: 1/250000. Disponível em: <ftp://geoftp.ibge.gov.br/mapas_tematicos/ geologia/cartas_escala_250mil/sh22vc_geol.pdf>. Acesso em: 09 jul. 2014.

. Geomorfologia. Santa Maria SH.22-V-C. Rio de Janeiro: IBGE, $2003 \mathrm{~b}$. 1 mapa. Escala: 1/250000. Disponível em: <ftp://geoftp.ibge.gov.br/mapas tematicos/geomorfologia/cartas_escala_250 mil/sh22vc_geom.pdfsg22yd_zc_ geom.pdf>. Acesso em: 09 jul. 2014.

. Censo agropecuário. Tabelas. Rio de Janeiro: IBGE, 2006. Disponível em: < < <ttp://www.ibge.gov.br/home/estatistica/economia/agropecuaria/ censoagro/1995_1996/43/>. Acesso em: 17 jul. 2014.

. Censo demográfico. Banco de Dados Agregados. Rio de Janeiro: $\overline{\mathrm{I}} \overline{\mathrm{B}} \overline{\mathrm{G}} \overline{\mathrm{E}}$, 2010. Disponível em: <http://www.sidra.ibge.gov.br/bda/tabela/protabl. $\mathrm{asp} ? \mathrm{c}=202 \& \mathrm{z}=\mathrm{t} \& \mathrm{o}=3 \& \mathrm{i}=\mathrm{P}>$. Acesso em: 17 jul. 2014.

.Cidades@. Rio de Janeiro: IBGE, 2014. Disponível em: <http://www. cidades.ibge.gov.br/xtras/perfil.php?lang $=\& \operatorname{cod}$ mun $=432065 \&$ search $=$ riogrande-do-sul|silveira-martins>. Acesso em: 25 jun. 2014.

LIMA, L. P. Z. et al. Análise da vulnerabilidade natural para implantação de unidades de conservação na microrregião da Serra de Carrancas, MG. Cerne, v. 17, n. 2, p. 151-159, 2011.

MESQUITA, C.; ASSIS, A. Q. S.; SOUZA, R. M. Vulnerabilidade natural à perda de solos da bacia hidrográfica do Rio Sagrado - Morretes/PR. Revista de Geografia, Especial VIII SINAGEO, n. 2, p. 249-264, 2010. 
PEREIRA, J. R. et al. Gestão social dos territórios da cidadania: o zoneamento ecológico-econômico como instrumento de gestão do território noroeste de Minas Gerais. Cadernos EBAPE.BR, v. 9, n. 3, p. 724-747, 2011.

ROVANI, F. F. M.; SARTORI, M. G. B.; CASSOL, R. Zoneamento ecológicoeconômico de Barão de Cotegipe, RS: potencialidade para o ordenamento do território. Revista Brasileira de Cartografia, v. 66, n. 1, p. 137-151, 2014.

ROVANI, F. F. M.; CASSOL, R.; WOLLMANN, C. A.; SIMIONI, J. P. D. Análise da vulnerabilidade natural à perda de solo de Barão de Cotegipe, RS. Revista do Departamento de Geografia, v. 29, n. 1, p. 264-282, 2015.

TRICART, J. Ecodinâmica. Rio de Janeiro: IBGE, 1977. 91 p.

SIMÕES, M. et al. Metodologia para elaboração do Zoneamento EcológicoEconômico em áreas com grande influência antrópica. Rio de Janeiro, 1998. Disponível em: <http://www.laget.igeo.ufrj.br/egler/pdf/maggie.pdf>. Acesso em: 02 jun. 2014.

STRECK, E. V. et al. Solos do Rio Grande do Sul. Porto Alegre: EMATER/RSASCAR, 2008. 222p.

Franciele Francisca Marmentini Rovani - Possui graduação em Geografia pela Universidade Federal de Santa Maria. Mestrado e doutorado em Geografia pela Universidade Federal de Santa Maria. Atualmente é professora Adjunta no Departamento de Geociências da Universidade Federal de Santa Catarina.

Márcio Viera - Possui graduação em Engenharia Florestal pela Universidade Federal de Santa Maria. Mestrado e doutorado em Engenharia Florestal pela Universidade Federal de Santa Maria. Atualmente é Professor Adjunto no Colégio Politécnico da Universidade Federal de Santa Maria.

\section{Contribuições dos autores}

Todos os autores ofereceram substanciais contribuições científicas e intelectuais ao estudo. As tarefas de concepção e design do estudo, preparação e redação do manuscrito, bem como a revisão crítica, foram desenvolvidas em conjunto. O primeiro autor ficou especialmente responsável pelo desenvolvimento teórico-conceitual e procedimentos técnicos; e o segundo autor, pela aquisição de dados e sua interpretação e análise. 